\title{
Discutir saúde e imigração no contexto atual de intensa mobilidade humana
}

Daniel Granada(a)

Ioná Carreno(b)

Natália Ramos ${ }^{(c)}$

Maria da Conceição Pereira Ramos (d)

Granada D, Carreno I, Ramos N, Ramos MCP. Debating health and migrations in a context of intense human mobility. Interface (Botucatu). 2017; 21(61):285-96.

This paper discusses the relationship between immigration and health in Brazil, from a historical approach seeking to put in context this debate from the nineteenth century to the present day. These relationships highlight the challenges of social policies of reception and integration of immigrants in a globalized world. Through literature review on immigration and health both in the Brazilian and the international context, we seek to reveal essential priorities to public health emerging from the present intense human mobility. Socioeconomic inequalities are the hallmark of the immigrants' experience, exposing these populations to greater vulnerability, illness and a reducing their quality of life. We conclude on the much needed promotion of equitable access to health, discrimination prevention, expansion of public policies, adequate training of professionals and offering services that are fitted to migrants, from the point of view of migration as a social determinant of health.

Keywords: Immigration. Public health. Primary health care. Quality of life. Public policies.
Este artigo aborda as relações entre imigração e saúde no Brasil, partindo de uma abordagem histórica que busca contextualizar o debate no país desde o século XIX até os dias atuais. A problematização dessas relações destaca os desafios das políticas sociais de acolhimento e integração dos imigrantes no mundo globalizado. Por meio da revisão bibliográfica sobre imigração e saúde no contexto brasileiro e internacional, buscamos prioridades que se impõem à saúde coletiva em face da intensa mobilidade humana atual. As desigualdades socioeconômicas marcam a experiência de parte dos imigrantes, expondo estas populações a uma maior vulnerabilidade, adoecimento e menor qualidade de vida. Apontamos a necessária promoção da equidade de acesso à saúde, prevenção contra a discriminação, ampliação das políticas públicas, formação dos profissionais e oferta de serviços adaptados, abordando a temática das migrações como determinante social de saúde.

Palavras-chave: Imigração. Saúde coletiva. Atenção básica de saúde. Qualidade de vida. Políticas públicas.

\footnotetext{
(a) Centro de Ciências Humanas e Sociais (CCHS), Univates. Rua Avelino Tallini, 171, Sala 213, prédio 2. Lajeado, RS, Brasil. 95900-000. dgdsferreira@ univates.br (b) Centro de Ciências Biológicas e da Saúde (CCBS), Univates. Lajeado, RS, Brasil. icarreno@univates.br (c) Centro de Estudos das Migrações e das Relações Interculturais (CEMRI), Universidade Aberta. Lisboa, Portugal. natalia@uab.pt

(d) CEMRI, Faculdade de Economia (FEP), Universidade do Porto (UP). Porto, Portugal. cramos@fep.up.pt
} 


\section{Introdução}

A mobilidade humana é um fenômeno histórico que acompanha o desenvolvimento das sociedades e a crescente globalização. O aumento significativo de pessoas que deixam os seus países tem se dado, sobretudo, devido às facilidades proporcionadas pelos avanços tecnológicos, que: reduzem os custos de transporte e comunicação e os espaços geográficos, facilitam as relações transnacionais, bem como proporcionam a queda de barreiras de circulação, aumentando o fluxo de bens, serviços, capital, conhecimento e ideias. As desigualdades de desenvolvimento econômico entre países e os conflitos políticos e armados também contribuíram para este aumento. $\mathrm{O}$ crescimento da imigração tem também acarretado políticas de controle migratório cada vez mais opressivas, com alto grau de seletividade, quase sempre baseadas em questões de segurança e em detrimento do aspecto humanitário ${ }^{1-4}$.

A mobilidade internacional tem fundamental importância na atualidade em função do aumento intenso e diversificado do fluxo e circulação humana e de deslocamentos forçados ou voluntários. A complexidade dos deslocamentos atuais coloca em evidência a necessidade de se construírem modelos explicativos abrangentes e interdisciplinares, que busquem alcançar a multifatorialidade na explicação dos fenômenos relacionados às migrações e saúde, e que se constituam na interface dos diferentes campos do saber ${ }^{5}$. Também é necessário compreender as dimensões escalares da imigração e buscar explicações que não derivem em particularismos idiossincráticos ou largas escalas em que se perde a dimensão dos indivíduos que compõem estes fluxos. Em se tratando de saúde, modelos comparativos e de médio alcance podem ser bastante produtivos na compreensão das relações entre imigração e saúde.

Este artigo, elaborado por meio da revisão bibliográfica sobre o tema, busca, inicialmente, abordar as relações entre saúde e imigração no Brasil numa perspectiva histórica, estendendo-se, em seguida, ao debate contemporâneo sobre imigração e saúde, tentando compreender as suas implicações quando pensamos as relações complexas entre saúde e imigração.

\section{Saúde e imigração em contexto histórico: um novo debate no Brasil?}

As relações entre saúde e imigração não são temas novos no Brasil. O país recebe historicamente vagas de imigrantes desde as suas origens. No final do século XIX, houve o período de chegada de imigrantes mais intenso no país, sobretudo portugueses, italianos e espanhóis, que vinham para realizar a substituição da mão de obra escrava e se integrar dentro do projeto de "branqueamento" da jovem república brasileira ${ }^{6-9}$. Imigrantes japoneses começam a se instalar a partir do início do século XX. Estima-se que o Brasil, no período entre o final do século XIX e início do século XX, acolheu, aproximadamente, 4,4 milhões de pessoas, vindas, sobretudo, de Portugal, Itália, mas, também, da Espanha, Japão e Alemanha, além de outros países ${ }^{10}$.

Estudos históricos e antropológicos ressaltam questões associadas às ideias sobre o "branqueamento" da população brasileira por meio da mistura das populações locais e aquelas de origem africana, com populações brancas de origem europeia, visando à melhoria da "raça" 6-9,11,12.

As ideias relativas ao "branqueamento" eram estruturadas sobre princípios do evolucionismo e dos determinismos raciais. Elas partiam de uma afirmação-chave, de que a miscigenação não produziria, inevitavelmente, "degenerados", mas uma população mestiça, que teria a capacidade de se tornar cada vez mais branca tanto fisicamente quanto em termos culturais ${ }^{9}$.

A imigração branca, portanto, teria como efeito reforçar a predominância dos brancos e fortalecer a população brasileira por intermédio da mistura. Entretanto, de acordo com Ramos e Maio, a doutrina do branqueamento era marcada por certa ambivalência em relação à mestiçagem, ora concebida como negativa, ora como positiva ${ }^{11}$. Esse pensamento tinha como base ideias sobre a diminuição da população negra com relação à branca por motivos associados: à suposta baixa fertilidade dos negros e mulatos, suposta inferioridade intelectual, maior incidência de doenças sobre esta população e a desorganização, além da tradição portuguesa de cruzamentos inter-raciais e a imigração europeia ${ }^{11}$.

Neste contexto, questões relacionadas à saúde e imigração fazem parte do debate no país, pelo menos, desde meados do século XIX, estando intimamente associadas à própria formação nacional. Chalhoub demonstra as relações entre a incidência da febre amarela que, segundo os registros, teria 
letalidade maior entre a população imigrante do que entre os negros durante o século XIX. O autor discorre sobre a falta de ação do governo com relação às doenças que atingiam, preferencialmente, os negros (tuberculose e varíola) em comparação com as doenças que atingiam mais diretamente os imigrantes recém-instalados no Brasil, como a febre amarela ${ }^{12}$. O fato de a epidemia manchar a imagem do Brasil no exterior faria com que o governo tornasse o seu combate uma de suas prioridades. Segundo Chalhoub, os médicos apoiariam a proposta imigrantista por meio de um viés racista e compartilhariam das ideias vigentes no período ${ }^{12}$. Para Maio, seriam as condições econômicas, sociais e sanitárias que marcariam a sociedade brasileira da época, o que teria influenciado a identificação dos médicos com as propostas imigrantistas ${ }^{13}$.

Na década de 1940, no período da Segunda Guerra Mundial, alemães vieram ao Brasil e foram vistos como ameaça à segurança da nação e possíveis colaboradores do regime nazista. A cidade de Rolândia (Paraná) é um exemplo de inadequação de acolhimento e respeito a esses imigrantes. Nessa cidade, instalou-se a "polícia política", que perseguia vários imigrantes alemães, levando até a exclusão do núcleo familiar e econômico, provocando inúmeras formas de adoecimento ${ }^{14}$.

Situação semelhante também ocorreu no Vale do Itajaí, em Santa Catarina, onde, no período entre 1937 e 1945, em função da "campanha de nacionalização" promovida pelo Estado Novo, visava-se à integração e caldeamento de todos os "alienígenas", e uma série de medidas foi tomada, durante a "campanha militar", para a tarefa de nacionalização. Essas políticas de nacionalização também ocorreram em outras partes do Brasil, como em São Leopoldo, no Rio Grande do Sul ${ }^{15}$.

No período de 1908 a 1942, mais de 188 mil japoneses imigraram para o Brasil, indo, inicialmente, para as fazendas de café e instalando-se, sobretudo, no estado de São Paulo. Na época, eram acusados de terem dificuldades de aculturação, a imigração japonesa sendo considerada um risco para a "raça em formação" no Brasil. Dessa forma, incentivou-se a entrada de europeus em detrimento dos japoneses ${ }^{16}$.

\section{Imigração e emigração no Brasil no contexto atual}

Os fluxos migratórios contemporâneos para e a partir do Brasil devem ser entendidos em sua diversidade e complexidade no contexto da globalização e internacionalização dos mercados de trabalho. Durante os anos de 1980, tem início um novo movimento populacional. Desta vez, são os brasileiros que decidem emigrar em busca de uma vida melhor e da ascensão social que lhes é negada pela situação no Brasil. Assim, milhares de brasileiros partem para trabalhar nos países do Norte, nomeadamente EUA ${ }^{17-23}$, mas, também, na Europa, especialmente em Portugal e Suíça ${ }^{24-31}$.

A primeira vaga de imigração brasileira em Portugal era composta por elevada proporção de profissionais qualificados originários da classe média brasileira, que chegaram a Portugal até meados da década de 1990 (quadros superiores e profissões liberais, como médicos, dentistas e empresários); a que se seguem mudanças no perfil socioeconômico dos imigrantes brasileiros, com menor grau de instrução e qualificação profissional, instalados em Portugal a partir dos finais dos anos 1990 (trabalhadores não especializados na construção civil, comércio, restauração, serviços domésticos, de limpeza, etc. $)^{3,29}$.

Os estrangeiros residentes oficialmente em Portugal representam, segundo o Censo de 2011, 4\% dos residentes no país, cerca de quatrocentas mil pessoas, e situam-se em uma faixa etária mais jovem do que as dos portugueses, sendo os brasileiros, os cabo-verdianos, os ucranianos e os romenos os mais representativos. Os brasileiros representam $28 \%$ dos estrangeiros residentes, e caracterizamse, também, por serem a comunidade em que a importância das mulheres é superior: $57,9 \%$ da comunidade brasileira ${ }^{32}$. A inserção dos imigrantes brasileiros no mercado de trabalho português é facilitada pela proximidade da língua.

Atualmente, no século XXI, a estabilidade econômica das últimas duas décadas tornou o Brasil novamente atraente para os estrangeiros. Este cenário evidencia a complexidade dos fluxos migratórios na atualidade, mostrando o Brasil, simultaneamente, como país de imigração e de emigração, mas, também, a mobilidade humana como uma das grandes chaves de produção e reprodução das desigualdades internacionais criadas pelo processo de globalização ${ }^{4,33}$. Por um lado, continua ocorrendo 
a emigração de brasileiros, ao mesmo tempo em que o país atrai novos fluxos de imigrantes. Além disso, é considerável o movimento de brasileiros que retornam ao país, sobretudo, em virtude da crise econômica, a partir de 2007, nos Estados Unidos e na Europa ${ }^{34}$. Atualmente, fazem parte destes fluxos: trabalhadores altamente qualificados, refugiados políticos, vítimas de catástrofes ambientais, estudantes, entre outros. Com relação aos motivos dos deslocamentos, devem ser levados em conta, além de questões laborais e econômicas, fatores como: reagrupamento familiar, refúgio e asilo ${ }^{35}$.

A presença de novos fluxos de imigração para o Brasil tem levantado questões sobre Direitos Humanos, sendo o acesso à saúde e a integração desta população na sociedade e no mercado de trabalho identificados como problemas a serem estudados. A produção acadêmica sobre o tema também tem acompanhado esse crescimento, enfocando diferentes aspectos relacionados às temáticas de imigração e emigração no Brasil ${ }^{36-39}$. Apesar dessa crescente produção, ainda são necessários estudos que analisem os efeitos da imigração e que considerem a questão escalar da imigração e seu impacto sobre populações em pequenas e médias cidades do interior do Brasil, ainda pouco estudadas. Faz-se necessário compreender o fenômeno da imigração dentro das especificidades dos territórios nos quais ele ocorre ${ }^{40}$. O território assume-se, efetivamente, como variável de desenvolvimento econômico e social associado à melhoria das condições de vida da população ${ }^{(e)}$.

\section{Saúde e imigração no Brasil contemporâneo}

A presença de novos fluxos de imigração para o Brasil tem levantado questões sobre o acesso à saúde e a integração desta população na sociedade e no mercado de trabalho local. Alguns estudos que relacionam a imigração e o acesso à saúde no Brasil foram realizados em São Paulo, com imigrantes bolivianos, e trazem resultados relevantes sobre as interfaces entre imigração e saúde. Em um deles, constatou-se um quadro crescente de patologias associadas às precárias condições de vida e de trabalho, ressaltou-se a alta presença de tuberculose (TBC) em um dos distritos da cidade, com maior incidência sobre a população imigrante em comparação com a população local ${ }^{42}$. A presença da tuberculose e de problemas dermatológicos e respiratórios também foi registrada em outro estudo sobre os imigrantes bolivianos em São Paulo, problemas que estão associados à precariedade das condições de vida e trabalho desta população ${ }^{43}$. Também na Europa e na América do Norte se verificaram estes mesmos problemas de saúde, assim como: uma maior frequência de mortalidade, morbidade, doenças graves, por exemplo, hepatite B e C e HIV- SIDA; mais comportamentos de risco para a saúde, como consumo de álcool, tabaco e drogas; mais estresse, problemas psicossomáticos, doença mental e física e menor qualidade de vida, nos imigrantes em situação de precariedade social|44-47.

Num estudo sobre bolivianos em São Paulo, foi identificada a existência de políticas nacionais e locais de acesso ao serviço de saúde para a população migrante, e assinalada, igualmente, a valorização positiva, por parte dos bolivianos, relativamente ao acesso ao Sistema Único de Saúde (SUS) dentro de um quadro comparativo com relação ao país de origem, onde o acesso aos serviços de saúde, apesar de ser universal como no Brasil, ainda se encontra em fase de implementação e menos desenvolvido que o brasileiro ${ }^{48}$.

Com relação aos imigrantes haitianos, um estudo realizado na cidade de Tabatinga, no Amazonas, mostra o impacto da chegada de um grande número de imigrantes na cidade de cerca cinquenta mil habitantes, situada na região

\author{
(e) A definição de território \\ empregada neste \\ trabalho segue o sentido \\ proposto pela geografia \\ francesa em que se \\ entende o território como \\ porção da face terrestre \\ apropriada, por grupos \\ sociais, para garantir sua \\ reprodução e a satisfação \\ de suas necessidades \\ vitais. Entidade espacial \\ e local de convivência \\ que é dele indissociável, \\ neste sentido se coloca \\ em evidência o território \\ como fruto da ação \\ humana, sendo que \\ sua produção acarreta \\ disputas de poder em \\ diferentes dimensões, \\ entre elas, as dimensões \\ econômica e social ${ }^{41}$ \\ No caso das migrações, \\ é particularmente \\ interessante compreender \\ estas disputas de poder \\ que ocorrem dentro das \\ relações de dominação \\ e de apropriação \\ que se desenvolvem \\ nos embates entre \\ populações migrantes \\ e locais, inclusive, no \\ acesso aos serviços de \\ saúde.
}


da fronteira do Brasil com Peru e Colômbia ${ }^{41}$. Os autores relatam casos de precariedade de condições de acolhimento, exploração dos imigrantes haitianos nos valores cobrados pelos aluguéis em residências frequentemente insalubres, além do "medo sanitário" fomentado pelos próprios moradores. Assinalam o impacto do processo migratório na saúde mental e física destes indivíduos, tendo sido relatados: maus-tratos sistemáticos relativamente ao tráfico de pessoas, irresolução administrativa, condições de alojamento desumanas, acesso insuficiente a alimentos, representações negativas no nível da população local, estereótipo e discriminação. Expõem, também, o vazio existente entre as diferentes esferas de governo para a atenção a esta população, e a preocupação de não se "facilitar" o acolhimento e a assistência, evitando-se uma possível intensificação do fluxo migratório, já considerado acelerado, para o município ${ }^{49}$.

Outro estudo analisa a saúde dos imigrantes haitianos, e assinala a falta de informação como fator dificultador de acesso aos serviços, considerando a avaliação dos serviços de saúde pelos haitianos como heterogênea: alguns avaliam positivamente o atendimento junto ao SUS, enquanto outros reclamam de demora no atendimento e dificuldade de acesso $\mathrm{O}^{50}$.

Outras temáticas relativas à condição que precede a inserção no circuito migratório, levantadas por Sayad, nos relembram que todo imigrante é, em sua terra natal, um emigrante ${ }^{51}$. Esta condição também precisa ser problematizada e compreendida, uma vez que uma das causas de sofrimento psicológico também se relaciona com o fato de que o projeto migratório, muitas vezes, é resultado de um esforço coletivo da família e parentes, que esperam a retribuição do emigrante uma vez instalado no país de destino; o que, no caso brasileiro, tem sido dificultado em função dos baixos salários pagos a grande parte dos imigrantes e das variações cambiais com a frequente desvalorização da moeda local em face do dólar ou do euro, gerando preocupação aos imigrantes que não conseguem retribuir o apoio recebido pelos familiares ${ }^{(f)}$.

No campo da saúde no Brasil atual, temos de considerar a questão dos

(f) $\mathrm{O}$ "sofrimento psicológico" envolve: sofrimento e dificuldades psíquicas e sociais tensões, conflitos e sentimentos dolorosos derivados de um conjunto complexo de relações entre o individual e o coletivo, bem como de mudanças, rupturas, perdas e traumas, de vulnerabilidades psíquicas e psicossociais, de problemas sociais, culturais, somáticos e psicológicos com que o indivíduo migrante se vê confrontado, e que podem afetar a sua saúde mental e física e a sua inserção social ${ }^{44,46,52-55}$ diferentes deslocamentos, dado que envolvem explicações multifatoriais em que existe a circulação desde trabalhadores para os postos mais baixos do mercado de trabalho, como no caso de haitianos, ganenses, senegaleses, bengalis, bolivianos, entre outros; e migrações pendulares, como no caso dos paraguaios e moradores de zonas fronteiriças, até o caso de "fuga de cérebros" (brain drain) por meio de programas governamentais, como o "mais médicos", com a instalação de médicos cubanos em centenas de cidades do Brasil, e trabalhadores diplomados altamente qualificados de países desenvolvidos que buscam melhor inserção no mercado de trabalho brasileiro e o desenvolvimento de uma carreira

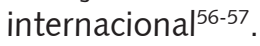

\section{Saúde e mobilidade humana}

O fenômeno da mobilidade humana envolve diversas modalidades, como: migrações internas, imigrações, emigrações, fluxos migratórios e refugiados. Para uns, a circulação é acelerada e facilitada com os passaportes biométricos e modalidades de transporte eficientes em custo e tempo. Já, para outros, migrar é, se não impossível, extremamente arriscado: rotas subterrâneas, vidas e trajetórias invisíveis, recursos escassos, e, se acaso chega ao destino, uma quantidade imensa de incertezas e privações.

Ao longo do tempo, observa-se que os imigrantes são grupos particularmente vulneráveis a uma diversidade de fatores que determinam as suas condições de saúde. No plano internacional, diversas questões têm sido levantadas com 
relação às especificidades da condição dos imigrantes e às desvantagens cumulativas sofridas por essa população no acesso à saúde. Há uma importância crescente do tema da saúde na agenda da União Europeia e na defesa da igualdade de acesso aos serviços prestados e melhoria da sua qualidade. A relação entre saúde e imigração ganha importância nas preocupações dos responsáveis políticos e dos investigadores que estudam a inserção e saúde dos imigrantes nos países de acolhimento. N. Ramos afirma que ${ }^{47}$ :

As questões dos direitos e da saúde das populações migrantes e minorias estão no centro das preocupações dos Estados, nomeadamente da União Europeia, onde se inclui Portugal. Com efeito, o direito à saúde constitui um direito fundamental indispensável para o exercício dos outros direitos humanos. (p. 7)

Os problemas relacionados com a imigração, a qualidade de vida e acesso à saúde aumentam com: as dificuldades comunicacionais, linguísticas e de adaptação no país de acolhimento, o confronto com o preconceito, o estereótipo e a discriminação, a aceitação de postos de trabalho pesados e mal remunerados e pouco reconhecidos socialmente, a falta de suporte social formal e informal, ou seja, isolamento, fracas redes sociais e dificuldade de informação e acesso aos serviços, designadamente de saúde $26-28,30,31,44-47$. Exposição ao isolamento social, aos processos de aculturação e sofrimento psicológico e doença decorrente deste processo, habitação precária e insalubre em regiões desfavorecidas e sujeitas a catástrofes naturais e violência, deficiência alimentar, uso de drogas e álcool, incidência de certas condições de trabalho, entre outros, são fatores que tornam esta população mais vulnerável que as populações locais ${ }^{58-64}$. Entretanto, num estudo realizado no Quebec, foi constatado que os imigrantes gozavam de melhor saúde que os locais e que recorriam menos aos serviços de saúde, seja por falta de informação seja por não sentirem necessidade, tratando-se de uma população jovem e mais saudável ${ }^{65}$. Os imigrantes podem não recorrer aos serviços de saúde por estas razões, mas também: por medo de serem denunciados no caso de estarem em situação irregular; por dificuldades linguísticas e culturais; por desconhecerem a legislação que regula os seus direitos, relevando questões de informação e de comunicação, nomeadamente no trabalho e na saúde 28,30,31,44-47.

A qualidade de vida associada às condições de trabalho dos imigrantes revela riscos laborais significativos, com repercussões na saúde e segurança no trabalho ${ }^{58}$. A não aplicação de normas de segurança e saúde tem potenciais consequências de acidentes e doenças profissionais. Os trabalhadores imigrantes tendem a estar mais representados em setores sensíveis às flutuações econômicas, mais expostos a trabalhos perigosos e menos saudáveis, com contratos menos seguros, temporários e com menor estabilidade de emprego, em ocupações menos qualificadas, em especial: na construção, serviços domésticos, atividades de limpeza, hotelaria, comércio, etcc $25,66,67$. As migrantes nos trabalhos domésticos referem: aspectos psicossociais, grandes exigências emocionais, escassa percepção de apoio, insegurança, monotonia, problemas de estresse, de sono, ansiedade, cansaço e tristeza, contexto de isolamento, sobretudo as empregadas "internas" 33.

Os debates acerca do acesso dos imigrantes aos cuidados de saúde estão relacionados com a inclusão ou não destes cidadãos nos sistemas de segurança social e nas políticas sociais e de acesso aos serviços em cada país, bem como nas políticas de imigração, de direitos humanos, de luta contra a discriminação e o racismo, e de coesão social68-71. A coesão social promove a capacidade de uma sociedade assegurar o bem-estar de todos os seus membros e de minimizar as desigualdades e polarizações.

Nas relações entre saúde e imigração, considera-se importante a perspectiva de busca de trabalho e melhores condições de vida fora do país de origem, colocando-se, cada vez mais, a ênfase em fatores de atração e repulsão como elementos centrais nos processos de saúde e doença dos indivíduos, bem como relacionados com relações de gênero, com a durabilidade dos projetos migratórios, com 
a circularidade e com a clandestinidade e desenvolvimento das redes internacionais das economias subterrâneas ${ }^{33,72,73}$. Assiste-se, também, ao rápido crescimento dos deslocamentos pendulares e sazonais e à existência de transmigrantes ${ }^{74}$. O migrante tem, cada vez mais, um estatuto de cidadão transnacional, estratégias de vida com múltiplas pertenças, culturas, identidades e nacionalidades ${ }^{75}$. "O aumento das comunidades e das práticas transnacionais encontra-se estreitamente associado às transformações ocorridas nas políticas de cidadania, nos valores culturais e representações relativas à mobilidade, identidade, lealdade e pertença"4 (p. 80).

Estudos sobre a ocorrência de doença e causa de morte dos imigrantes assinalam que estes adotam menos medidas de saúde preventivas, recorrendo, sobretudo, aos médicos e hospitais em caso de emergência ou em estado avançado de doença; apresentam taxas elevadas de desnutrição, problemas respiratórios e intestinais, diarreia, doenças infecciosas (especialmente, as crianças), como malária, tuberculose e infecção por HIV; são objeto de diversas formas de discriminação, violência e precariedade socioeconômica que afetam a sua saúde mental, física e qualidade de vida, vindo agravar o problema a situação de clandestinidade/irregularidade, de exclusão social e de não reconhecimento da diferença, da singularidade do outro ${ }^{44,46,76}$. A OMS refere como prioritário: o acesso aos determinantes de saúde (moradia, alimentação, saneamento e acesso à informação e aos serviços de saúde, entre outros), o combate às vulnerabilidades, desigualdades sociais, pobreza e discriminação, fatores que influenciam a saúde dos imigrantes ${ }^{77}$.

Desse modo, pensar a imigração e suas relações com os determinantes sociais de saúde nos levaria a interrogar sobre a posição social na qual o imigrante se insere. Na medida em que, no caso da imigração de baixa qualificação profissional, o imigrante se insere nos postos mais baixos e menos remunerados na sociedade de acolhimento, ele estará exposto às condições ambientais e sociais que provocam uma maior vulnerabilidade ao adoecimento, conforme mostram os estudos acima citados. Convém, portanto, analisar as relações entre saúde e imigração no caso brasileiro, considerando a perspectiva que tem sido seguida por pesquisadores no caso da Europa ou dos Estados Unidos, em que se advoga a compreensão do próprio fenômeno migratório como um determinante social de saúde complexo e multifatorial, com impacto nas populações deslocadas ou acolhidas, bem como nas populações locais em ambos os polos do circuito ${ }^{78-80}$.

\section{Considerações finais}

O problema das desigualdades socioeconômicas marca a experiência cotidiana de uma grande parte dos imigrantes no acesso ao trabalho, moradia, educação e condições ambientais adequadas, bem como as condições sanitárias e psicossociais. As dificuldades específicas de certos grupos de imigrantes (estatuto jurídico legal ou irregular, domínio da língua do país de acolhimento, analfabetismo, diferentes representações culturais da saúde, da doença e do corpo, informação deficitária ou insuficiente, entre outros) tornam particularmente vulnerável a saúde e bem-estar de determinados grupos de migrantes. As relações entre os processos migratórios e a saúde são atravessadas pela complexidade e multifatorialidade, em que se encontram e concorrem diferentes "sistemas culturais de saúde" que exigem respostas eficientes por parte dos profissionais e gestores dos sistemas oficiais de saúde ${ }^{81}$.

As sociedades multiculturais constituem um desafio aos direitos de cidadania, ao reconhecimento da alteridade e à integração de populações migrantes. As conclusões apontam para: a importância da compreensão das especificidades da população migrante, necessidade de aumento da sua qualidade de vida, promoção da equidade de acesso à saúde, nomeadamente no trabalho, luta contra as desigualdades, discriminação e preconceito, desenvolvimento das políticas públicas e oferta de serviços adaptados às novas demandas dos imigrantes. Os aspetos multidimensionais da saúde e qualidade de vida devem ser conjugados com políticas públicas eficazes. 


\section{Colaboradores}

Os autores participaram, igualmente, de todas as etapas de elaboração do artigo.

\section{Referências}

1. Barreto A, organizador. Globalização e migrações. Lisboa: ICS; 2005.

2. Castles S. Globalização, transnacionalismo e novos fluxos migratórios. Lisboa: Edições Fim de Século; 2005.

3. Ramos MC. Globalização, políticas sociais e multiculturalidade. In Rubim A, Ramos N, organizadores. Estudos da cultura no Brasil e em Portugal. Salvador: EDUFBA; 2008. p. $145-82$.

4. Ramos MCP. Globalização e multiculturalismo. Rev Eletron Inter-Legere. 2013; 13:75-101.

5. Goldberg A, Martin D, Silveira C. Editorial. São Paulo: Rev Interfaces. 2015; 19(53):229-32.

6. Schwarcz LM. O espetáculo das raças: cientistas, instituições e questão racial no Brasil 1870-1930. São Paulo: Companhia das Letras; 1995.

7. Seyferth G. As identidades dos imigrantes e o melting pot nacional. Horiz Antropol. 2000; 6(14):143-76.

8. Seyferth G. Construindo a nação: hierarquias raciais e o papel do racismo na política de imigração e colonização. In: Maio MC, Santos RV. Raça, ciência e sociedade. Rio de Janeiro: Fiocruz, Centro Cultural Banco do Brasil; 1996.

9. Skidmore TE. Preto no branco: raça e nacionalidade no pensamento brasileiro. Rio de Janeiro: Paz e Terra; 1989.

10. Levy MSF. O papel da imigração internacional na evolução da população brasileira (1872 a 1972). Rev Saude Publica. 1974; 8Supl:49-90.

11. Ramos JS, Maio MC. Entre riqueza natural, a pobreza humana e os imperativos da civilização, inventa-se a investigação do povo brasileiro. In: Maio MC, Santos RV, organizadores. Raça como questão. História, ciência e identidades no Brasil. Rio de Janeiro: Fiocruz; 2010. p. 38.

12. Chalhoub S. The politics of disease control: yellow fever and race in nineteenth century. J Lat Am Stud. 1993; 25(3):441-63.

13. Maio MC. Raça, doença e saúde pública no Brasil: um debate sobre o pensamento higienista do século XIX. In: Maio MC, Santos RV, organizadores. Raça como questão. História, ciência e identidades no Brasil. Rio de Janeiro: Fiocruz; 2010. p. 38.

14. Priori A, Ipólito VK. DOPS, a cidade de Rolândia (PR) e a repressão aos imigrantes de origem alemã (1942-1945). Varia Hist. 2015; 31(56):547-80.

15. Seyferth G. A assimilação dos imigrantes como questão nacional. Mana. 1997; 3(1):95-131.

16. Mota A, Marinho MGSMC, Silveira C, organizadores. Saúde e história de migrantes e imigrantes. Direitos, instituições e circularidades. São Paulo: USP, Faculdade de Medicina, UFABC, Universidade Federal do ABC, Casa de Soluções e Editora; 2014.

17. Margolis M. Little Brazil: imigrantes brasileiros em Nova York. Campinas: Papirus; 1994.

18. Patarra NL. Migrações internacionais de e para o Brasil contemporâneo: volumes, fluxos, significados e políticas. São Paulo Perspect. 2005; 19(3):23-33. 
19. Margolis M. Na virada do milênio a imigração brasileira para os Estados Unidos. In: Martes ACB, Fleischer S, organizadoras. Fronteiras cruzadas: etnicidade, gênero e redes. São Paulo: Paz e Terra; 2003. p. 51-72.

20. Martes ACB. Brasileiros nos Estados Unidos - um estudo sobre imigrantes em Massachusetts. São Paulo: Paz e Terra; 1999.

21. Martes ACB. Raça e etnicidade - opções e constrangimentos. In: Martes ACB, Fleischer $S$, organizadoras. Fronteiras cruzadas: etnicidade, gênero e redes. São Paulo: Paz e Terra; 2003. p. 73-98.

22. Reis R, Sales T, organizadores. Cenas de um Brasil migrante. São Paulo: Boitempo; 1999.

23. Ribeiro GL. O que faz o Brasil, Brazil: jogos identitários em São Francisco. In: Cenas do Brasil migrante. São Paulo: Boitempo; 1999. p. 45-85.

24. Ramos MP. Le Portugal, de l'émigration à l'immigration. Rev Santé Soc Solidarité. 2005; 4(1):203-15.

25. Ramos MCP. Imigração, desenvolvimento e competitividade em Portugal. Econ Sociol. 2007; 84:71-108.

26. Franken I, Coutinho MP, Ramos N. Migração e qualidade de vida, o pensamento social de brasileiros migrantes. In: Krutzen EC, Vieira SB, organizadores. Psicologia Social, Clínica e Saúde Mental. João Pessoa: EDUFPB; 2007. p. 160-79.

27. Franken I, Coutinho MP, Ramos N. Migração, qualidade de vida e saúde mental: um estudo com brasileiros migrantes. In: Ramos N, organizador. Saúde, migração e interculturalidade. João Pessoa: EDUFPB; 2008. p. 177-211.

28. Franken I, Coutinho MP, Ramos N. Migração e qualidade de vida: um estudo psicossocial com brasileiros migrantes. Estud Psicol. 2009; 26(4):419-27.

29. Torresan A. A middle class besieged: Brazilians' motives to migrate. J Lat Am Caribb Anthropol. 2012; 17(1):110-30.

30. Reis L, Ramos N. Imigrantes brasileiros em Lisboa e utilização dos serviços de saúde. In: Padilha B, Rodrigues E, Masanet E, Fernandes G, Gomes MS, França T. Novas e Velhas Configurações da Imigração brasileira na Europa. Livro de Atas - $2^{\circ}$ Seminário de Estudos sobre a Imigração Brasileira na Europa. Lisboa: CIES, IUL, 2012; p. 105-11.

31. Reis $L$, Ramos N. Migração e saúde de brasileiros residentes em Lisboa. Ambivalências. 2013; 1(2): 29-53.

32. Instituto Nacional de Estatística (PT). Destaque - a população estrangeira em Portugal 2011. Lisboa: INE; 2012.

33. Ramos N. Migrações, tráfico de pessoas e trabalho doméstico. Rev Polit Publicas. 2014; 18(2):425-38.

34. Fernandes $D$, Nunan $C$, Carvalho $M$. O fenómeno da migração internacional de retorno como consequência da crise mundial. Rev Estud Demogr. 2011; 49:69-98.

35. Cavalcanti L. Imigração e mercado de trabalho no Brasil. Características e tendências. In: Cavalcanti L, Oliveira AT, Tonhati T, organizadores. A inserção dos imigrantes no mercado de trabalho brasileiro. Brasília: Cadernos do Observatório das Migrações Internacionais; 2015. p. 11-22.

36. Ferreira AP, Vainer $C$, Póvoa Neto $H$, Santos $M O$. A experiência migrante: entre deslocamentos e reconstruções. Rio de Janeiro: Faperj, Garamond; 2010.

37. Silva AS, organizador. Migrações na Pan-Amazônia. Fluxo, fronteiras e processos socioculturais. São Paulo: Hucitec; Manaus: Fapeam; 2012. 
38. Zanini MC, Póvoa Neto H, Santos $M$, organizadores. Migrações internacionais: valores, capitais e práticas em deslocamento. Santa Maria: UFSM; 2013.

39. Cavalcanti L, Oliveira AT, Tonhati T, organizadores. A inserção dos imigrantes no mercado de trabalho brasileiro. Relatório Anual 2015. Brasília, DF: Observatório das Migrações Internacionais, Ministério do Trabalho e Previdência Social, Conselho Nacional de Imigração e Coordenação Geral de Imigração; 2015.

40. Schiller NG, Çaglar A. Introduction: migrants and cities. In: Schiller NG, Çağlar A, editores. Locating migration. New York: Cornell University Press; 2011. p. 1-22.

41. Paquot T. Qu'est-ce qu'un territoire ? Vie Soc. 2011; 2(2):23-32.

42. Goldberg A, Silveira C. Desigualdad social, condiciones de acceso a la salud pública y procesos de atención en inmigrantes bolivianos de Buenos Aires y São Paulo: una indagación comparativa. Saude Soc [Internet]. 2013 [citado 21 Ago 2015]; 22(2):283-97.

43. Melo RA, Campinas LLSL. Multiculturalidade e morbidade referida por imigrantes bolivianos na Estratégia Saúde da Família. O Mundo da Saúde. 2010; 34(1):25-35.

44. Ramos N. Saúde, migração e interculturalidade. João Pessoa: EDUFBA; 2008.

45. Ramos N. Saúde, migração e direitos humanos. Mudanças Psicol Saude. 2009; 17(1):1-11.

46. Ramos N. Psicologia clínica e da saúde. Lisboa: Universidade Aberta; 2004.

47. Ramos N. Comunicação em saúde e interculturalidade: perspectivas teóricas, metodológicas e práticas. RECIIS - Rev Eletron Comum Inov Saude. 2012; 6(4):1-19.

48. Martes ACB, Faleiros SM. Acesso dos imigrantes bolivianos aos serviços públicos de saúde na cidade de São Paulo. Saude Soc. 2013; 22(2):351-64.

49. Véran J-F, Noal DS, Fainstat T. Nem refugiados, nem migrantes: a chegada dos haitianos à cidade de Tabatinga (Amazonas). Dados. 2014; 57(4):1007-41.

50. Fernandes D, Castro MCG. Projeto de estudos sobre imigração haitiana no Brasil, diálogo bi-lateral - relatório de pesquisa [Internet]. Puc Minas; 2014 [citado 19 Jul 2015]. Disponível em: obs.org.br/cooperacao/ download/34_7a099729afe2d4aaf109503e6daf3908.

51. Sayad A. Imigração ou os paradoxos da alteridade. São Paulo: Edusp; 1998.

52. Fassin D. Et la souffrance devint sociale. De l'anthropologie médicale à une anthropologie des afflictions. Critique. 2004; 1(680-681):16-29.

53. Furtos J. Précarité du monde et souffrance psychique. Rhizome. 2001; 5:3-5.

54. Jacques P. Souffrance psychique et souffrance sociale. Pensée Plurielle. 2004; 2(8):21-9.

55. Kaës R. Souffrance psychique et violence de civilisation. Rhizome. 2001; 5:1-2.

56. Ramos MCP. Mobilidades qualificadas e empreendedoras no contexto dos movimentos migratórios contemporâneos e da crise económica. Ambivalencias. 2013; 1(2):73-99.

57. Fracalossi C, Ramos MC. Mobilidade internacional e desenvolvimento da carreira de jovens migrantes portugueses qualificados no Brasil. Tomo. 2015; 26:11-35.

58. Ramos MCP, Patrício O. Riscos laborais de homens e mulheres migrantes e segurança no trabalho. In: Silva IC, Pignatelli M, Viegas SM, coordenador. Livro de Atas do $1^{\circ}$ Congresso da Associação Internacional de Ciências Sociais e Humanas em Língua Portuguesa. Lisboa: CONLAB, FCSH-UL; 2015. p. 2948-55.

59. Bäckström B, Carvalho A, Inglês U. Imigração e saúde - o gabinete de saúde do CNAI enquanto observatório para o estudo das condições de acesso dos imigrantes aos serviços de saúde. Migrações. 2009; 4:161-89. 
60. Solé-Auró A, Crimmins E. Health of immigrants in European countries. Int Migr Rev. 2008; 41(4):861-76.

61. Scheppers E, Van Dongen E, Dekker J, Geertzen J, Dekker J. Potential barriers to the use of health services among ethnic minorities: a review. Family Pract. 2006; 23(3):325-48.

62. Huijts T, Kraaykamp G. Immigrants' health in Europe: a cross-classified multilevel approach to examine origin country, destination country, and community effects. Int Migr Rev. 2012; 46(1):101-37.

63. Mirdal GM. Stress, distress in migration: twenty years after. Int Migr Rev. 2006; 40(2):375-89.

64. Challinor EP. Cidadania médica, culturas e poder nos cuidados perinatais e pediátricos de imigrantes. Saude Soc. 2012; 21(1):76-88.

65. Clarkson M. La santé des immigrants récents au Québec: une intégration à adapter et à parfaire. Santé Soc Solidarité. 2005; 4(1):121-8.

66. Eurofound. Employment and working conditions of migrant workers. Dublin: European Foundation for the Improvement of Living and Working Conditions; 2007.

67. Eamranond $\mathrm{P}, \mathrm{Hu} \mathrm{H}$. Environmental exposures in immigrant health. Environ Health Insights. 2008; 1:45-50.

68. Santos BS. Por uma concepção multicultural de direitos humanos. Rev Crit Cienc Soc. 1997; 48:11-32.

69. Ramos MP. Immigration, droits de I'homme et construction européenne. Dialogos. 2002; 5:23-6.

70. OIT. Trabalhadoras e trabalhadores migrantes: alcançar a igualdade de direitos e oportunidades. Lisboa: OIT, Trabalho digno para todos; 2008.

71. Taran P, Ivakhnyuk I, Ramos MCP, Tanner A. Economic migration, social cohesion and development: an integrated approach. Strasbourg: Conseil de l'Europe; 2009.

72. Tarrius A. Au-dela des États-nations: des sociétés de migrants. Rev Eur Migr Int. 2001; 17(2):37-61.

73. Tarrius A. Le lien social fort comme préalable à la réussite économique. J Anthropol [Internet]. 2001; 84 [citado 01 Jan 2002]. Disponível em: http://jda.revues.org/2592.

74. Basch L, Schiller NG, Blanc CS. Nations unbound: transnational projects, postcolonial predicaments and the deterritorialized nation-state. New York: Gordon and Breach; 1994. p. 48.

75. Ramos M, Teixeira A, Pereira M, Gonçalves M. Multiple citizenship. case-studies among individual citizens in Portugal. In: Pitkanen P, Kalekin-Fishman D, editors. Multiple state membership and citizenship in the era of transnational migration. Rotterdam: Sense Publishers; 2007. p. 41-65.

76. Ramos N. Migrações e alteridade: desafios para a saúde colectiva. In: Teixeira L, Rodrigues S, organizadores. Psicanálise, saberes e práticas em saúde. Curitiba: Ed. PR, CRV; 2015. p. 271-300.

77. Comission on Social Determinants of Health. Action on the Social Determinants of Health: learning from previous experiences. Geneva: WHO; 2005.

78. Castañeda H, Holmes SM, Madrigal DS, Young MET, Beyeler N, Quesada J. Immigration as a social determinant of health. Annu Rev Public Health. 2015; 36:375-92.

79. Padilla B. Saúde dos imigrantes: multidimensionalidade, desigualdades e acessibilidade em Portugal. REMHU - Rev Interdiscip Mobil Hum. 2013; 21(40):49-68. 
80. Carballo M, Divino J, Zeric D. Migration and health in the European Union. Trop Med Int Health. 1998; 3(12):936-44. doi:10.1046/j.1365-3156.1998.00337.x.

81. Langdon EJ, Wiik FB. Anthropology, health and illness: an introduction to the concept of culture applied to the health sciences. Rev Latino-Am Enfermagem. 2010; 18(3):459-66.

Granada D, Carreno I, Ramos N, Ramos MCP. Discutir sobre salud e inmigración en el contexto actual de intensa movilidad humana. Interface (Botucatu). 2017; 21(61):285-96.

Este artículo aborda las relaciones entre inmigración y salud en Brasil, partiendo de un abordaje histórico que busca la contextualización del debate en el país desde el siglo XIX hasta los días actuales. La problematización de esas relaciones subraya los desafíos de las políticas sociales de acogida e integración de los inmigrantes en el mundo globalizado. Por medio de la revisión bibliográfica sobre inmigración y salud en el contexto brasileño e internacional, buscamos prioridades que se imponen a la salud colectiva frente a la intensa movilidad humana actual. Las desigualdades socio-económicas marcan la experiencia por parte de los inmigrantes, exponiendo a esas poblaciones a una mayor vulnerabilidad, enfermedad y menor calidad de vida. Señalamos la necesaria promoción de la equidad de acceso a la salud, prevención contra la discriminación, ampliación de las políticas públicas, formación de los profesionales y oferta de servicios adaptados, abordando la temática de las migraciones como factor determinante social de salud.

Palabras-clave: Inmigración. Salud colectiva. Atención básica de salud. Calidad de vida. Políticas públicas. 